\title{
Developing Thought Leaders: An Industry Practicum Approach
}

\author{
Keith L. Herndon, Ph.D. \\ Professor of Practice, University of Georgia \\ Ryan Kor-Sins, M.A. \\ Doctoral Student, University of Utah
}

\begin{abstract}
This innovative practice paper discusses how a journalism training practicum empowers and emboldens participants to think critically about their professional goals and allows them to emerge not only with new technical skills but also as industry thought leaders. The news industry is facing a profound technological upheaval as the majority of news consumers turn to their smartphones for content. News organizations need workers with skills and competencies suited to this new environment, but they also need those infused with an entrepreneurial spirit willing to take on significant structural challenges within an industry that honors tradition. In this practicum, thought leadership is emphasized as a desired byproduct of a training model that relies heavily on coaching.
\end{abstract}

\section{Introduction}

In early April 2015, one of our practicum students bounded into the office and, beaming with pride, quickly opened her Twitter feed. "Achievement unlocked!" the post proclaimed. A major U.S. software company had tweeted to the world about how the student and her team were the first to use its product for mobile reporting (Twitter, 2015 - full citation not included to protect student privacy). These students, searching for new ways to present news content on their mobile devices, had found a tool intended for business presentations and personal diaries and decided to experiment with it. The project worked and the young student journalists had not only learned new skills involving a new distribution platform but, in the process, had emerged as thought leaders. Two years later, another student sent an urgent email detailing how her team's story package had been selected for promotion on her team's platform of choice. Traffic to the story was climbing into the tens of thousands of viewers. The team had selected a mobile presentation platform rarely used for news, but their content drew the attention of the platform hosts. Yet again, a mobile project had transformed students from experimenters into thought leaders as they learned valuable lessons about the power of content promotion in an era of information clutter.

These are only two of dozens of examples where students began our practicum training in mobile news with loosely formed projects and emerged with something uniquely compelling. They worked their ideas into projects designed to experiment with new forms of content creation and distribution, while overcoming technology and production obstacles. While the practicum's training sessions equip these students with new skills required in contemporary newsrooms, the overriding goal is to steep students in a critical thinking process that gives them confidence to perform as project leaders and as reverse mentors in an industry increasingly turning to its younger workers for thought leadership (Herndon and Krueger, 2016). 
What makes this practicum particularly innovative is that it both equips students with technical and industry skills, and teaches them how to be thought leaders by encouraging creative thinking, out-of-the-box ideas, and attention to emerging trends. Training thought leaders requires participants who are willing to go out of their comfort zones and who accept that at times they will fail. The emphasis on process rather than results also helps make this approach innovative.

\section{Review of Related Scholarship}

The rise of smartphone usage in the last decade has profoundly changed the way people consume news media. Mobile news allows users constant access to news content whenever and wherever they want it. Through their mobile devices, people are continuously connected to the internet and can access timely information faster than ever before and through new media usage contexts (Wolf \& Schnauber, 2015). Although mobile news is beneficial for its convenience and immediacy, it has serious implications for the sustainability of traditional news outlets (Mitchell \& Holcomb, 2016).

Internet and mobile news consumption has caused a steady decline in the viability of legacy media models. Although digital advertising sales rose 20 percent in 2016, such sales only make up a fraction of the revenue necessary to keep the newspaper industry afloat (Mitchell \& Holcomb, 2016). According to a Pew Research Center report, "It has been evident for several years that the financial realities of the web are not friendly to news entities" (Mitchell \& Holcomb, 2016). Many mobile users are now turning to social media outlets such as Twitter and Facebook to get aggregated news - a practice that further weakens traditional news outlets' ability to capitalize on online ad revenue.

Many traditional news outlets have expanded their business model to include online and mobile content. In a 2010 global newspaper industry survey, 51 percent of media managers indicated that mobile platforms were an important priority for the future (Westlund, 2013). The most common way that traditional media outlets have begun to create a mobile presence is by repurposing print or online content for mobile devices. However, some question whether this practice is innovative enough to drive traffic to a legacy news outlet's mobile site. Nguyen (2008) observed that "as the traditional media have been establishing their Web presence to make sure that they will exist in the future, they have largely failed to bring the innovative potential of online news into play" (p. 7).

Although mobile news has been, in many ways, detrimental to legacy news, it does open a new avenue for innovative journalistic practices. New formats for mobile news stories, such as list-based articles, and emerging technologies, such as virtual reality, have transformed the way readers experience news content (Beynon, 2014; Polgreen, 2014). Mobile news has also become increasingly more personalized by allowing users to control a multitude of options tailored to their specific interests. By embracing news consumption at the individual level, journalists can break with a traditionalism that has a tendency to stifle innovation (Wolf \& Schnauber, 2015). It is now the task of publishers to monetize mobile news through innovative practices. 
The tremendous change that the news industry has undergone in recent years necessitates a heightened level of innovation and flexibility. Such flexibility is not commonly seen in a traditional newsroom setting (Nguyen, 2008). Because of this, it is essential for news organizations to seek employees who display traits of thought leadership. According to Alhaddi (2015), "thought leadership starts with the spark of a new idea and ends with the implementation readiness for the idea" (p. 2). Thus, a thought leader is an early adopter of innovation who acts as a champion for that innovation and paves the way for new ideas to be accepted and implemented (Alhaddi, 2014).

Thought leadership exists when innovation is present. Although innovation and thought leadership are closely linked, the two terms are not interchangeable (McCrimmon, 2005). Innovation involves the creation of a new product or concept, while thought leadership refers to the advocacy of that innovation (Alhaddi, 2014). In a sense, thought leadership picks up where innovation leaves off. Thought leadership works seamlessly between the areas of innovation creation and innovation implementation by modeling the advantages of the innovation through example. Thought leadership does not necessarily lead to action; rather, it changes the way people think (McCrimmon, 2005).

One of the attributes that makes thought leadership uniquely powerful is its distinction from traditional, hierarchical leadership. While traditional leadership involves management of subordinates and relies on authority to accomplish goals, thought leadership removes the power dynamic and instead rests on the merits of the idea to influence others to change their actions (McCrimmon, 2005). Thought leadership is about advocating new ideas rather than directing people to act or working toward a specific goal (McCrimmon, 2005). Consequently, thought leaders can lead without directly managing anyone and can therefore influence their peers, and more importantly, their superiors. According to Kurtzman (1998), thought leaders answer "the big questions with which today's most senior executives are wrestling” (p. 58). The ability of a thought leader to champion emerging ideas and influence people at all levels of power is exactly what makes them such valuable assets in the workplace. In practice, thought leadership manifests itself in a variety of ways. According to McCrimmon (2005),

Some thought leaders are quiet innovators who, lacking influencing skills, must demonstrate the merits of their ideas. Other thought leaders are not personally creative but they are early adopters of new technology or new ways of doing something, and hence, quick to champion new ideas. Thought leadership can range from high risk, revolutionary products through minor changes to operating procedures.

(p.

Despite this variety, thought leaders share some defining characteristics. They have strong intuition and can sense and seize innovation (Heath, Singh, Ganesh, \& Taube, 2013). Simply put, thought leaders are responsible for "setting trends in the market for ideas" (Frick, Guetler, \& Gloor, 2013). 


\section{Description of the Practice}

Zeichner (1996) believed a practicum should be structured so that students are not merely showing off what they already know; instead, it should provide a forum for student development and should foster new learning. With this notion in mind, our practicum is structured to encourage experimentation and to challenge the status quo as students develop and design projects. It is structured around four areas: skills instruction, field work, professional coaching, and reflection on the work created. We understand that practicums are not unique to journalism education. Therefore, we turned to research from a variety of fields such as education, engineering, law, and social work for insights into how practicums can be organized, delivered, and assessed (Grose, 2013; Regher, Regher, Bogo, \& Power, 2007; Schulz, 2005; Waitz \& Barrett, 1997). Drawing from this material, we created a practicum framework based on team projects that emphasizes skills development processes.

Researchers at Griffith University concluded that "generic skills," including such things as teamwork, communication, analysis, and problem-solving, can be developed within university students if they perceive their importance and are allowed to practice them (Crebert, Bates, Bell, Patrick, \& Cragnolini, 2004). Our practicum is based on these ideas with students told why the assignments are structured as they are and why and how the teams will be held accountable for the work they produce.

Students are taught basic competencies that enable them to develop news content for mobile devices and are also instructed on best practices for journalists in an industry wrought with change. To encourage students to strive to produce the best work possible, all major assignments are both peer and professionally reviewed. This means that students evaluate each other's work and give feedback in addition to industry professionals reviewing and giving suggestions to the students as tasks unfold. Finally, the students engage in self-reflection after they complete each assignment. This ensures that students think through their decision-making processes and seek to understand how their successes and failures were in many cases due to their own choices.

The Griffith University study also informed our structure, which relies heavily on industry guest participation as trainers, speakers, and coaches. The Griffith researchers suggested that leadership and entrepreneurial skills and the ability to take responsibility and make decisions are skills more likely to be developed in a workplace setting than an academic setting (Crebert et al., 2004). Given this finding and because we wanted to emphasize these characteristics, we felt it important to bring the workplace into the practicum by having industry professionals play key roles. However, as Greenberg (2007) observed "in journalism education the relationship between theory and practice is hotly contested - perhaps more so than in other practice-based subjects" (p. 289). Such tensions were not dismissed out of hand when conceptualizing the framework for our practicum. Rather, we considered the relationship between theory and practice extensively but concluded that the innate nature of a practicum required a vocational approach. Therefore, our framework features vocational training through an emphasis on developing emerging skill sets. We believe this approach has standing in the pedagogical approaches and traditions of journalism education, which has a long history of emphasizing vocational skills development (Greenberg, 2007). 
With a conceptual framework in place, the next step was to test the approach through a pilot project that launched in the Fall 2014 semester. The pilot featured seven students working on projects overseen by a dedicated faculty mentor and industry practitioners from two major news organizations. The initial practicum was offered as a non-credit, extracurricular activity, with volunteer participants recruited from a pool of students with practical experience through campus media or internships. These students were divided into two teams. One worked on a project emphasizing data visualization, and the other worked to optimize video presentations on smartphones and tablets. The projects allowed us to ask and explore several questions related to project development and completion, including how often meetings should be held and how often students should have contact with the faculty mentor and industry coaches. We learned that because it was a non-credit offering, meeting more than once weekly was problematic; students simply prioritized their credit course requirements over a non-credit practicum.

For the Spring 2015 semester, we offered the practicum as a 3-hour credit course under a provision for "special topics." This allowed us to experiment with the practicum as a credit offering without going through full curriculum approval to make it a permanent course. As a credit course, enrollment was capped at 16 students organized into four teams of four students each. The faculty mentor became the professor of record for the course, but the projects were once again led by industry practitioners from two major news organizations. Immediately following the conclusion of the spring semester, the practicum was offered again as a special topic credit course, but this time through the shortened Maymester program offered at our university. The shortened approached allowed the professor and industry guests to fashion the practicum more like a workshop. However, the shortened timeframe compressed the project timelines and created significant stress for the six enrolled students who wanted to create meaningful projects.

\section{Discussion of Outcomes/Results}

In the two cases when the practicum was offered for credit, the professor of record and the industry coaches reached important conclusions that resulted in the final structure we now have for the program. First, we concluded that a full semester was too long and that a Maymester was too short. Second, we found that a practicum rooted in experimentation required students to accept that some experiments would fail. When offered for credit and the associated grading that comes with that, students found it difficult to accept grading based on process rather than on the final outcomes of their experiments. With grades introduced into the practicum, the students wanted their experiments to succeed, and they tended to reduce their level of risk-taking, which undermined the goals of the program.

Consequently, our practicum delivery has settled into a non-credit model with students engaged as an extracurricular activity. Rather than a grade, they are rewarded upon completion with a workforce development certificate from a regional business organization that will resonate with some potential employers. The project workload is designed to closely resemble the time commitment a student would associate with a part-time internship or engagement with campus media. We also have limited the practicum to 10 weeks, which allows us to recruit participants at the beginning of a semester and for students to conclude their projects before they are consumed by end-of-semester projects and exams in their credit courses. 
We have offered the practicum during the past three fall semesters and will continue with this schedule for the foreseeable future. As noted in the introduction, there are numerous examples of students using their projects to achieve unique results through this process and to emerge as thought leaders. The program also has received industry recognition for its innovative approach to teaching production skills needed in mobile media (Freeman, 2015).

Collins (2015) asked the following in her article about leadership development in journalism education: "Are we training, educating, and building leaders who are prepared to challenge the status quo or maintain the status quo?" (p. 3). Her work looked mostly at the roles of gender in newsroom leadership, but her conclusion that newsrooms need transformational leaders to rise above the status quo speaks to our premise as well. She promoted the notion that students must be trained to be unafraid to lead. We have created a program that addresses the need for developing transformational leadership skills, which is training built on infusing students with critical thinking skills.

\section{Recommendations}

Cunningham (2002) wrote in the Columbia Journalism Review about the obligation of journalism education:

If the profession said all we want are people who can do some technique, then it is our duty to decline. It is not worthy of a great university to produce graduates who know a technique and nothing else. But I don't think that's what the profession wants. (p. 23).

We agree with Cunningham's assessment and believe the fundamental shift in how people receive and consume information over the past 15 years since he wrote those words underscore his premise. A journalism education that prepares today's students for the chaotic media world they will enter demands programs that reward experimentation and teach them how to learn from failed experiments. Critical thinking skills flow from such environments, and our need to prepare not only technicians but also thought leaders requires practicums with those outcomes in mind. After six cohorts using different delivery methods, we have, as stated earlier, settled on a noncredit model that encourages students to be creative and entrepreneurial. As we move forward with our next cohort, we are implementing recommendations from student assessments related to changes to the team structure and interaction with industry coaches.

Students have expressed the desire for their teams to be structured around specific delivery functions that are based on skills assessments. This recommendation means pairing strong writers and videographers with strong designers and technologists. We are deploying an assessment tool developed by a colleague to assist with team assignments. Students have also asked for more interaction with their industry coaches as they have found the relationships to be empowering. In our program follow-up assessments, students consistently compare the practicum to an internship largely because of the interaction they have with professionals (Cox Institute, 2015). This indicates to us that we are delivering a program in keeping with the framework and structure we set out to establish, but we want to address the student recommendation for more professional interaction with their coaches by encouraging video chats and social media engagement between the in-person meetings. 
For leadership educators and educators from other disciplines seeking to create their own experiential learning practicum, our recommendations can be summarized in three key takeaways: 1) establish the practicum as a non-credit extracurricular activity so as to remove grading from the process and to encourage risk-taking, 2) structure the duration and activities of the practicum to closely resemble the workload of a part-time internship and require participation, and 3) use industry practitioners as project coaches to enhance the professional nature of the training and to bridge the classroom with the workplace.

As for our program, we intend to continue experimenting with delivery and coaching models as technology changes and industry conditions warrant. A news industry executive said any company in the journalism field "who overlooks mobile is probably sacrificing their business" (Cox Institute, 2016). Our practicum was developed so that our students do not sacrifice their careers.

\section{References}

Alhaddi, H. (2014). The relationship between thought leadership and innovation: A look at strategy. Journal of Business Administration and Education, 6(2), 57-65.

Alhaddi, H. (2015). Innovators or thought leaders: What do organizations need? International Journal of Managerial Studies and Research, 2(3), 54-58.

Beynon, W. (2014). What the rise and rise of the listicle means for intellectual property. The Guardian. Retrieved from https://www.theguardian.com/media-network/media-networkblog/2014/may/20/rise-listicle-intellectual-property-buzzfeed

Collins, J. M. (2015). Leadership development in college newsroom labs: It is transactional. Journalism \& Mass Communication Educator. doi: 1077695815612323.

Cox Institute for Journalism Innovation, Management and Leadership. (2015). Grady students complete Spring 2015 Mobile News Lab [Press release]. Retrieved from http://grady. uga.edu/CoxInstitute/activities/grady-students-complete-spring-2015/

Cox Institute for Journalism Innovation, Management and Leadership (2016). Grady students complete Fall 2016 Mobile News Lab [Press release]. Retrieved from http://grady. uga.edu/CoxInstitute/activities/grady-students-complete-fall-2016-mobile-news-lab/

Crebert, G., Bates, M., Bell, B., Patrick, C-J., \& Cragnolini, V. (2004). Developing generic skills at university, during work placement and in employment: Graduates' perceptions. Higher Education Research \& Development, 23(2), 147-165.

Cunningham, B. (2002). Searching for the perfect J-school. Columbia Journalism Review, 41(4), 20-29. 
Freeman, S. (2015). Herndon named an Atlanta Mobility Star for 2015 [Press release of the Grady College of Journalism and Mass Communication at the University of Georgia]. Retrieved from http://grady.uga.edu/herndon-named-an-atlanta-mobility-star-for-2015

Frick, K., Guertler, D., \& Gloor, P. A. (2013). Coolhunting for the world's thought leaders. Paper presented at the COINs13 Conference, Chile. Retrieved from https://arxiv.org/abs/1308.1160

Grose, C. (2013). Beyond skills training, revisited: The clinical education spiral. Clinical Law Review, 19, 489-515.

Greenberg, S. (2007). Theory and practice in journalism education. Journal of Media Practice, 8(3), 289-303.

Heath, D., Singh, R., Ganesh, J., \& Taube, L. (2013). Building thought leadership through business-to-business social media engagement at Infosys. MIS Quarterly Executive, 12(2).

Herndon, K. L., \& Krueger, V. (2016). Leadership training in an industry context: Preparing student leaders for a chaotic news media. Journal of Leadership Education, 15(2), 48-57.

Kurtzman, J. (1998). Thought leaders: Insights on the future of business. San Francisco, CA: Jossey-Bass.

Nguyen, A. (2008). Facing "the fabulous monster": The traditional media's fear-driven innovation culture in the development of online news. Journalism Studies, 9(1), 91-104.

McCrimmon, M. (2005). Thought leadership: A radical departure from traditional, positional leadership. Management Decision, 43(7/8), 1064-1070.

Mitchell, A., \& Holcomb, J. (2016, June 15). State of the news media 2016. Washington, DC: Pew Research Center. Retrieved from http://www.journalism.org/2016/06/15/state-ofthe-news-media-2016/

Polgreen, E. (2014). Virtual reality is the next journalism frontier. Columbia Journalism Review. Retrieved from http://www.cjr.org/innovations/virtual_reality_journalism.php

Regher, C., Regher G., Bogo, M., \& Power R. (2007). Can we build a better mousetrap? Improving the measures of practice performance in the field practicum. Journal of Social Work Education, 43(2), 327-343.

Schulz, R. (2005). The practicum: More than practice. Canadian Journal of Education, 28(1\&2), $147-167$.

Twitter. (2015). Full citation not included to protect student privacy. 
Waitz, I. A., \& Barrett, E. C. (1997). Integrated teaching of experimental and communication skills to undergraduate aerospace engineering students. Journal of Engineering Education, 86(3), 255-262.

Westlund, O. (2013). Mobile news: A review and model of journalism in an age of mobile media. Digital Journalism, 1(1), 6-26.

Wolf, C., \& Schnauber, A. (2015). News consumption in the mobile era: The role of mobile devices and traditional journalism's content within the user's information repertoire. Digital Journalism, 3(5), 759-776.

Zeichner, K. (1996). Designing educative practicum experiences for prospective teachers. In Zeichner, K., Melnick, S., \& Gomez, M. (Eds.), Currents of reform in preservice teacher education (pp. 215-234). New York, NY: Teachers College Press.

\section{Author Biographies}

Keith L. Herndon, Ph.D., (klhern@uga.edu) is a Professor of Practice in Journalism at the University of Georgia's Grady College. He holds the William S. Morris Chair in News Strategy and Management and is the Director of the James M. Cox Jr. Institute for Journalism Innovation, Management and Leadership.

Ryan Kor-Sins, M.A., (ryan1kor@gmail.com) is a Ph.D. student in the department of Communication at the University of Utah. She earned her Master's Degree at the University of Georgia in Mass Communication Studies. Currently, she studies political polarization and contested truth in the context of digital news sites and rhetorical communication. 